\title{
Evaluation of effective factors in the acceptance of mobile health technology using the unified theory of acceptance and use of technology (UTAUT), case study: Blood transfusion complications in thalassemia patients
}

\author{
Shirindokht Farhady ${ }^{1}$, Mohammad Mehdi Sepehri*1 (D), Ali Akbar Pourfathollah² \\ Received: 20 Dec 2018 \\ Published: 22 Jul 2020
}

\section{Abstract}

Background: Mobile health or MHealth refers to the use of mobile phone in healthcare services to enhance the health level of people. Before using MHealth, it is necessary to study the effective factors in physicians' adoption and acceptance of technology in the field of thalassemia.

Methods: This cross sectional study was conducted using the survey and correlation methods. The statistical population of the study consisted of hematologists who were selected using the convenience sampling method. In this study, 58 questionnaires along with structural equations modeling based on partial least squares were used. SPSS and SMART PLS2 were used for data analysis. P values less than 0.05 were considered as statistically significant.

Results: Based on the outcomes of the model from all theories, the coefficient of variation seems to be positive and the possibility of test is lower than $5 \%$. The results indicated that all factors introduced in the proposed model are significantly effective in MHealth technology adoption.

Conclusion: In this study, using the inputs from hematologists in hospitals and clinics in Tehran, it was aimed to find the factors affecting the hematologists' decision to use mobile health technology in reducing the complications of blood transfusion in patients with thalassemia who needed blood transfusion. Thus, plans were made determine to priorities and the existing conditions to implement this new system. Also, the strengths and weaknesses of each factor were measured to improve the weaker factors. UTAUT was used to determine the acceptance factors. After reviewing the results, the use of this model is recommended to physicians.

Keywords: Mobile Health, Unified Theory of Acceptance and Use of Technology (UTAUT), Thalassemia Patients

Conflicts of Interest: None declared

Funding: Tarbiat Modares University

\section{*This work has been published under CC BY-NC-SA 1.0 license.}

Copyright $($ Iran University of Medical Sciences

Cite this article as: Farhady Sh, Sepehri MM, Pourfathollah AA. Evaluation of effective factors in the acceptance of mobile health technology using the unified theory of acceptance and use of technology (UTAUT), case study: Blood transfusion complications in thalassemia patients. Med J Islam Repub Iran. 2020 (22 Jul);34:83. https://doi.org/10.47176/mjiri.34.83

Introduction

Mobile health or MHealth means providing everyone with healthcare services anytime and anywhere by elimi-
Corresponding author:Dr Mohammad Mehdi Sepehri, mehdi.sepehri@modares.ac.ir

1. Department of Industrial Engineering, Faculty of Industrial and Systems Engineering, Tarbiat Modares University, Tehran, Iran

2. Department of Immunology, Faculty of Medical Science, Tarbiat Modares University, Tehran, Iran $\uparrow$ What is "already known" in this topic:

Mobile health refers to the use of mobile phone in healthcare services, which has had a high growth rate due to the rapid advancements in IT technology. In the absence of legal and regulatory laws, many nurses and physicians do not recommend the use of mobile health programs.

$\rightarrow$ What this article adds:

A challenge in the path of development of mobile health technology is how to incorporate such system into physicians and nurses' practice. Thus, studying the effective factors to ensure acceptance and establishment of MHealth is highly important in the field of thalassemia. 
nating the constraints of time and place, while both the coverage and the quality of the health care indices increase (1, 2). In fact, rapid advancements in IT technology, particularly wireless and mobile communications, has led to the advent of a new information infrastructure that potentially supports the arrangement of services in advanced MHealth for healthcare $(3,4)$. The beauty of technology relies on the fact that it is not limited to a specific country or region. This technology has broadly extended in the world. Nowadays, mobile phone technology significantly influences healthcare outcomes and implications in developing countries (5). In the absence of legal and regulated views, many physicians do not recommend using apps. However, it was estimated that 1.5 billion mobile phone users would have used these apps worldwide by 2018 (6).

In 2018, Bawack and Kamdjoug examined the adequacy of the unified theory of acceptance and use of technology (UTAUT) in developing countries. They found physicians did not tend to accept this theory (7). In the same year, Venugopal et al (8) using the unified theory of acceptance and use of technology (UTAUT), observed that expected effort and social influence could have a significant effect on behavioral intention and facilitating conditions. In another study (9), the authors put forward the initial framework of health technology in developing countries via the unified theory of acceptance and use of technology (UTAUT). Moreover, they demonstrated that the given theory could not suffice to predict the acceptance of information technology (IT) in the framework of health systems strengthening (HSS). Furthermore, Shareef et al (10) investigated the impact of short message services (SMS) via smartphones on mobile health. They showed a positive role of the model developed based on the unified theory of acceptance and use of technology (UTAUT) in anticipating consumer perceptions of mobile technology with a focus on SMS. Hsieh et al (11) found PMT and UTAUT were effective in predicting the behavior of PHR use. Ease of use was also considered as a determinant affecting the PHR use. To examine public acceptance model of mobile health services, Dwivedi et al (12) presented that mobile service system was required to reflect cultural characteristics of each country.

In a review study performed in 2016, Garavand et al (13) shed light on the acceptance of mobile health technology in a recent research in which it had been revealed that factors such as perceived ease of use, perceived usefulness, and facilitating conditions could increase the percentage of acceptance of mobile health system. In another research, Bozan et al (14) evaluated the impact of social influence on IT acceptance by the elderly by the unified theory of acceptance and use of UTAUT. The gained consequences showed that older people were accustomed to sticking to recommendations by their physicians and were less accepting of technologies. Brown et al (15) used a mixed research approach to measure the health IT usability evaluation model (health-ITUEM) in the mobile health domain. The results demonstrated the usability of the ITUEM framework in assessing mobile health technology.

Using electronic health records (EHR) can greatly im- prove the quality of treatment with respect to cost-effectiveness, elimination of paperwork, and easy access to patients' information (16). In 1994, Aydin and Ischar came up with the results that older and more traditional physicians were less inclined to use computers in the treatment process. In addition to the preceding information, Brown and Kenney also demonstrated the positive influence of computer experience and computer skills on the adoption of computer systems for the treatment of patients (17).

The convenience of learning is a factor for doctors to adopt and work with the new system, because if learning and working with this system is difficult for physicians who are the main users of the system, they would prefer to use paper files (18). MHealth technology can also be used to help patients with thalassemia to reduce the side-effects of blood transfusion (19). A challenge in the path of development of mobile health technology is how to incorporate it in physicians and nurses' practice. Considering that any new technology is initially facing resistance from some users, identifying and implementing the effective factors in adopting this technology for users is essential. A large number of models and theories are available for adopting modern technologies. Important factors in accepting any technology can be listed as below:

- Establishing an appropriate strategy for implementation consistent with organizational goals;

- Measuring the quality of active processes;

- Allowing intervention of users at all phases;

- Investing in IT (20).

In this study, using compatibility of applying technologies and their related factors, including expected efficacy, expected effort, social impact, and facilitating conditions, we aimed to find effective factors in adoption and acceptance of using mobile health technology among hematologists using the unified theory of acceptance and UTAUT.

\section{Methods}

This was cross sectional study. To build the model the following sources were used to collect information: (1) books, articles, and documents; (2) resources in the domain of electronic health: written interviews, interviews with experts and students, and medical records; (3) internet search for articles in Science Direct, IEEE, Elsevier, etc. The reliability of the questionnaire calculated using Cronbach's alpha was 0.876 , which indicates its high reliability and its content validity was confirmed by experts.

In 2002, Chau and $\mathrm{Hu}$ (21) introduced a framework for the adoption of telemedicine technology. This framework was designed according to UTAUT and focuses on social and technical issues. In this study, we present a conceptual framework that is adapted from Chu et al model (22) (Fig. 1).

The literature conducted from 1997 to 2018 was reviewed by searching library references and Google Scholar, PubMed, Science Direct, and ProQuest databases. The search was performed using the following key words: applications, preventive care, and m-health. The identified articles were examined based on the objective of the present 


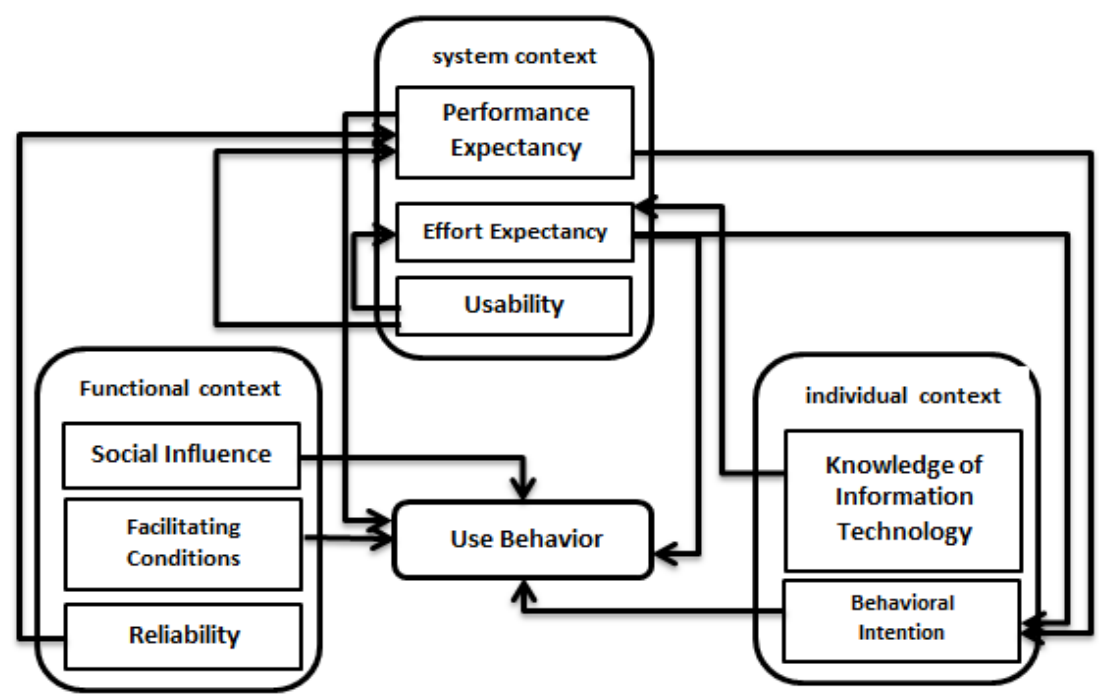

Moderating factors: age, gender, computer work experience. doctor's specialty. medical history

Fig. 1. Conceptual framework of the research

study. Out of 450 relevant articles, 19 were identified based on their titles. Eventually, 13 articles were selected for the survey based on inclusion and exclusion criteria (Fig. 2).
After designing the theoretical model (adoption and acceptance of mobile health technology among hematologists based on the UTAUT model provided by $\mathrm{Chau}$ and $\mathrm{Hu}$ and

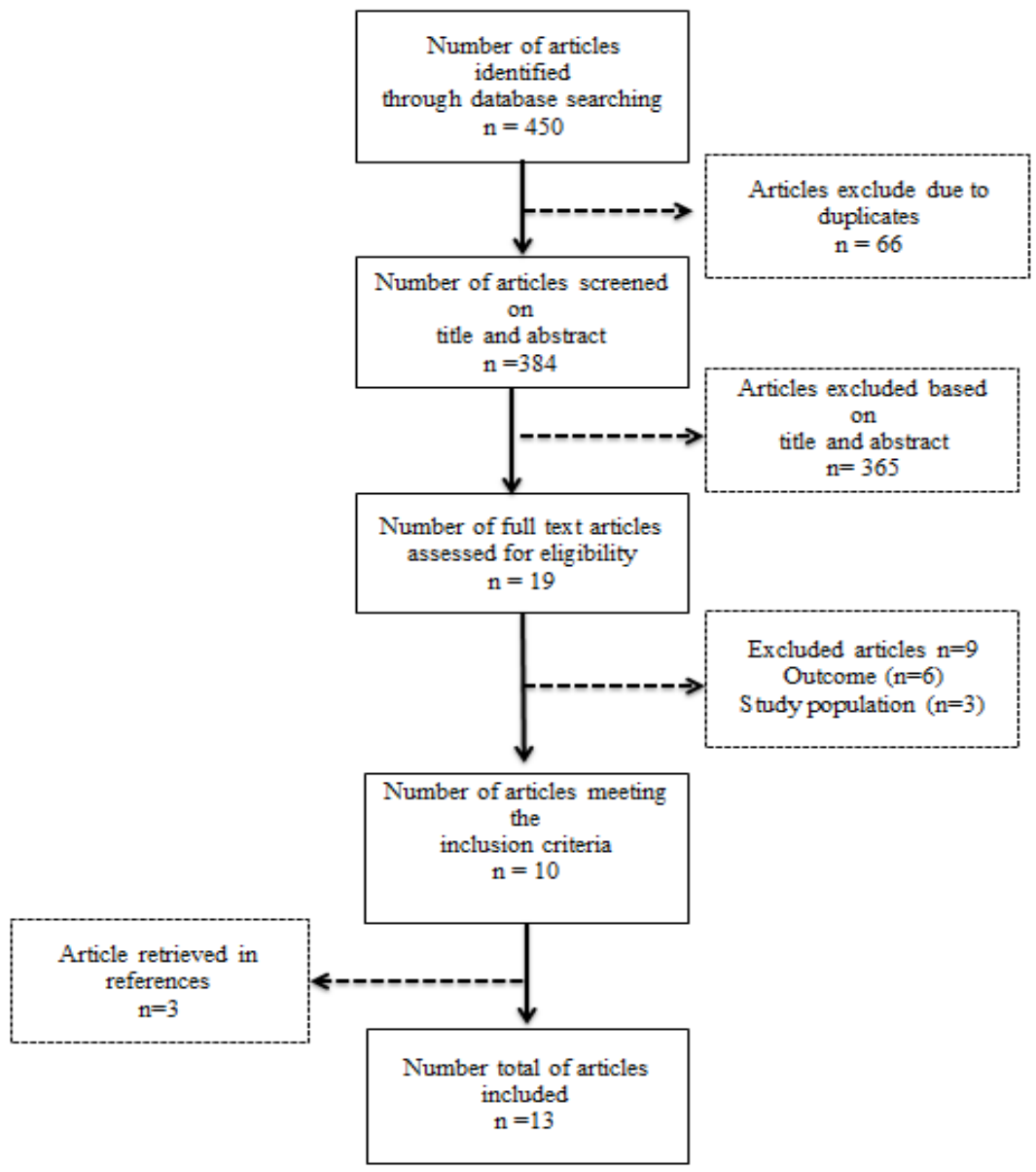

Fig. 2. Flow chart study selection procedure used in the literature search 
approved by the experts panel), the questioners were distributed among 58 hematologists community of experts who had been selected by convenience sampling method. After collecting the data, structural equations modeling based on partial least squares was used for data analysis.

\section{Data Analysis}

In this study, the Cronbach's alpha $(>0.7)$ and composite reliability $(>0.7)$ were used for questioner reliability. In addition, average variance extracted $(\mathrm{AVE})>0.5$ and confirmatory factor analysis were used to approve the validity of the questioner.

The numbers obtained from the AVE square root of each construct should be greater than the correlation of that construct with other constructs, which means that each number above the column is supposed to be greater than its lower and upper numbers. The acceptable validity of the model can be gained by comparing the obtained values from the AVE square root of the model constructs with the correlation coefficient of each construct with other constructs.

In this study, the model designed in the qualitative phase was estimated and analyzed using variance base structural equation method and partial least squares analysis method. In this model the value of $t$ presents the significance of variables' effect. The value of $t$ greater than 1.96 indicates a significant positive effect, between 1.96 and -1.96 a nonsignificant, and smaller than -1.96 a significant negative effect. Moreover, the path coefficients above 0.6 indicates a strong correlation between the 2 variables, between 0.3 and 0.6 a moderate correlation, and less than 0.3 a weak association.

The SMART PLS2 and SPSS version 18 were used for data analysis.

In this study Pearson correlation was used to examine the correlation among latent variables. Also, $\mathrm{p}$ value less than 0.05 was considered as statistically significant.

\section{Results}

This study was conducted on 32 men and 26 women. The acceptable factor loading is 0.7 for each factor with a significance level of 0.1 . Thus, factors with a factor loading less than 0.7 were excluded from the model. The results from testing items consistency showed that all items had a factor loading greater than 0.7 . Therefore, the internal consistency of the items was confirmed.

The results indicate that all model constructs have acceptable combinatory validity. This presents the satisfaction of the second condition of the reliability of the model. Moreover, in this study the Cronbach's reliability coefficient of all variables was at least 0.6 . Table 1 shows the

Table 1. Investigating the composite reliability of each structure

\begin{tabular}{|c|c|c|c|c|c|c|c|c|c|}
\hline \multicolumn{4}{|l|}{ Items } & \multicolumn{2}{|c|}{$\begin{array}{c}\text { Average variance extracted for } \\
\text { the items (AVE) }\end{array}$} & \multicolumn{2}{|c|}{$\begin{array}{l}\text { Composite reliability } \\
\text { of each structure }\end{array}$} & \multicolumn{2}{|c|}{ Cronbach's alpha } \\
\hline \multicolumn{4}{|c|}{ Use behavior } & \multicolumn{2}{|c|}{0.721324} & \multicolumn{2}{|c|}{0.928185} & \multicolumn{2}{|c|}{0.902988} \\
\hline \multicolumn{4}{|c|}{ Behavioral intention } & \multicolumn{2}{|c|}{0.662744} & \multicolumn{2}{|c|}{0.850810} & \multicolumn{2}{|c|}{0.736081} \\
\hline \multicolumn{4}{|c|}{ Effort expectancy } & \multicolumn{2}{|c|}{0.600673} & \multicolumn{2}{|c|}{0.811899} & \multicolumn{2}{|c|}{0.660448} \\
\hline \multicolumn{4}{|c|}{ Facilitating conditions } & \multicolumn{2}{|c|}{0.772529} & \multicolumn{2}{|c|}{0.944213} & \multicolumn{2}{|c|}{0.925413} \\
\hline \multicolumn{4}{|c|}{ Knowledge of information technology } & \multicolumn{2}{|c|}{0.681384} & \multicolumn{2}{|c|}{0.893417} & \multicolumn{2}{|c|}{0.838208} \\
\hline \multicolumn{4}{|c|}{ Performance expectancy } & \multicolumn{2}{|c|}{0.570702} & \multicolumn{2}{|c|}{0.870641} & & 506 \\
\hline Reliabil & & & & 0.65 & 671 & & 8927 & & 912 \\
\hline Social i & ience & & & 0.69 & 529 & & 9239 & & 646 \\
\hline Usabilit & & & & 0.77 & 100 & & 4062 & & 413 \\
\hline & & & & & & & & & \\
\hline Items & $\begin{array}{l}\text { Performance } \\
\text { Expectancy }\end{array}$ & $\begin{array}{l}\text { Effort Ex- } \\
\text { pectancy }\end{array}$ & $\begin{array}{l}\text { Social In- } \\
\text { fluence }\end{array}$ & $\begin{array}{l}\text { Facilitating } \\
\text { conditions }\end{array}$ & $\begin{array}{l}\text { Knowledge } \\
\text { of } \\
\text { Information } \\
\text { Technology }\end{array}$ & Usability & Reliability & $\begin{array}{c}\text { Use } \\
\text { Behavior }\end{array}$ & $\begin{array}{l}\text { Behavioral } \\
\text { Intention }\end{array}$ \\
\hline Q1 & 0.899 & 0.340 & 0.661 & 0.744 & 0.738 & 0.776 & 0.666 & 0.777 & 0.591 \\
\hline Q2 & 0.948 & 0.179 & 0.584 & 0.771 & 0.683 & 0.681 & 0.571 & 0.682 & 0.496 \\
\hline Q3 & 0.900 & 0.115 & 0.427 & 0.642 & 0.537 & 0.520 & 0.410 & 0.621 & 0.335 \\
\hline Q4 & 0.841 & 0.079 & 0.392 & 0.590 & 0.459 & 0.445 & 0.335 & 0.646 & 0.260 \\
\hline Q5 & 0.110 & 0.828 & 0.318 & 0.259 & 0.162 & 0.245 & 0.135 & 0.354 & 0.060 \\
\hline Q6 & 0.221 & 0.736 & 0.367 & 0.324 & 0.143 & 0.237 & 0.127 & 0.562 & 0.052 \\
\hline Q7 & 0.147 & 0.767 & 0.225 & 0.228 & 0.142 & 0.210 & 0.100 & 0.589 & 0.025 \\
\hline Q8 & 0.533 & 0.327 & 0.904 & 0.731 & 0.539 & 0.619 & 0.509 & 0.320 & 0.434 \\
\hline Q9 & 0.429 & 0.269 & 0.881 & 0.609 & 0.402 & 0.473 & 0.363 & 0.674 & 0.288 \\
\hline Q10 & 0.548 & 0.318 & 0.756 & 0.605 & 0.579 & 0.517 & 0.407 & 0.618 & 0.332 \\
\hline Q11 & 0.512 & 0.251 & 0.873 & 0.697 & 0.471 & 0.483 & 0.373 & 0.714 & 0.298 \\
\hline Q12 & 0.706 & 0.270 & 0.913 & 0.738 & 0.694 & 0.809 & 0.699 & 0.510 & 0.624 \\
\hline Q13 & 0.627 & 0.235 & 0.788 & 0.828 & 0.589 & 0.625 & 0.515 & 0.326 & 0.440 \\
\hline Q14 & 0.713 & 0.282 & 0.612 & 0.910 & 0.753 & 0.791 & 0.781 & 0.592 & 0.706 \\
\hline Q15 & 0.655 & 0.343 & 0.673 & 0.932 & 0.660 & 0.803 & 0.693 & 0.504 & 0.618 \\
\hline Q16 & 0.778 & 0.272 & 0.581 & 0.886 & 0.730 & 0.768 & 0.658 & 0.469 & 0.583 \\
\hline Q17 & 0.831 & 0.247 & 0.540 & 0.868 & 0.750 & 0.749 & 0.639 & 0.450 & 0.564 \\
\hline Q18 & 0.721 & 0.227 & 0.623 & 0.803 & 0.941 & 0.832 & 0.722 & 0.533 & 0.647 \\
\hline Q19 & 0.553 & 0.090 & 0.478 & 0.639 & 0.918 & 0.715 & 0.605 & 0.416 & 0.530 \\
\hline Q20 & 0.688 & 0.239 & 0.638 & 0.851 & 0.977 & 0.842 & 0.732 & 0.543 & 0.657 \\
\hline Q21 & 0.675 & 0.271 & 0.61 & 0.837 & 0.984 & 0.807 & 0.697 & 0.508 & 0.622 \\
\hline Q22 & 0.686 & 0.267 & 0.623 & 0.857 & 0.808 & 0.98 & 0.87 & 0.681 & 0.795 \\
\hline
\end{tabular}


Sh. Farhady, et al.

\begin{tabular}{|c|c|c|c|c|c|c|c|c|c|}
\hline Items & $\begin{array}{l}\text { Performance } \\
\text { Expectancy }\end{array}$ & $\begin{array}{l}\text { Effort Ex- } \\
\text { pectancy }\end{array}$ & $\begin{array}{l}\text { Social In- } \\
\text { fluence }\end{array}$ & $\begin{array}{c}\text { Facilitating } \\
\text { conditions }\end{array}$ & $\begin{array}{c}\text { Knowledge } \\
\text { of } \\
\text { Information } \\
\text { Technology }\end{array}$ & Usability & Reliability & $\begin{array}{c}\text { Use } \\
\text { Behavior }\end{array}$ & $\begin{array}{c}\text { Behavioral } \\
\text { Intention }\end{array}$ \\
\hline Q23 & 0.254 & 0.579 & 0.818 & 0.699 & 0.745 & 0.901 & 0.791 & 0.602 & 0.716 \\
\hline Q24 & 0.135 & 0.521 & 0.763 & 0.657 & 0.677 & 0.948 & 0.838 & 0.649 & 0.763 \\
\hline Q25 & 0.082 & 0.415 & 0.682 & 0.55 & 0.554 & 0.911 & 0.801 & 0.612 & 0.726 \\
\hline Q25 & 0.061 & 0.378 & 0.611 & 0.458 & 0.468 & 0.84 & 0.73 & 0.542 & 0.655 \\
\hline Q26 & 0.157 & 0.475 & 0.482 & 0.502 & 0.438 & 0.788 & 0.678 & 0.489 & 0.603 \\
\hline Q27 & 0.225 & 0.537 & 0.485 & 0.647 & 0.485 & 0.547 & 0.898 & 0.249 & 0.362 \\
\hline Q28 & 0.194 & 0.556 & 0.361 & 0.501 & 0.330 & 0.399 & 0.872 & 0.100 & 0.214 \\
\hline Q29 & 0.144 & 0.688 & 0.700 & 0.626 & 0.684 & 0.797 & 0.6 & 0.902 & 0.805 \\
\hline Q30 & 0.197 & 0.745 & 0.588 & 0.666 & 0.531 & 0.572 & 0.641 & 0.943 & 0.693 \\
\hline Q31 & 0.127 & 0.535 & 0.708 & 0.644 & 0.737 & 0.781 & 0.618 & 0.920 & 0.813 \\
\hline Q32 & 0.185 & 0.607 & 0.643 & 0.605 & 0.631 & 0.779 & 0.58 & 0.881 & 0.748 \\
\hline Q33 & 0.165 & 0.498 & 0.751 & 0.613 & 0.699 & 0.75 & 0.587 & 0.889 & 0.756 \\
\hline Q34 & 0.103 & 0.569 & 0.682 & 0.85 & 0.840 & 0.799 & 0.811 & 0.740 & 0.976 \\
\hline Q35 & 0.108 & 0.404 & 0.671 & 0.841 & 0.815 & 0.614 & 0.699 & 0.837 & 0.983 \\
\hline Q36 & 0.084 & 0.573 & 0.683 & 0.867 & 0.820 & 0.732 & 0.522 & 0.708 & 0.982 \\
\hline
\end{tabular}

results of the test of the combined validity of each construct.

Acceptable values for this criterion suggesting the validity of the measuring instruments is 0.5 . These values are indicated in Table 1, ie, AVE. The results of AVE for each construct indicate that the third condition of the model's reliability has been satisfied and the value of the extracted variance for each construct is more than an acceptable value of 0.5 .

\section{Examination of cross loading of items}

Table 2 presents the results of the cross loading of each item on its construct and other constructs. The factor loading of each item on its construct must be at least 0.1 more than the factor loading of that item on other constructs.

The cross loading related to model items is acceptable, and the factor loading of each item on its construct is at least 0.1 more than the factor loading of the same item on other constructs (Table 3 ).

\section{Examining the correlation among latent variables}

Table 3 shows the correlation matrix among the latent variables from the PLS algorithm test, where the diameter of the matrix has been replaced with the AVE square root

Table 3. Correlation between latent variables

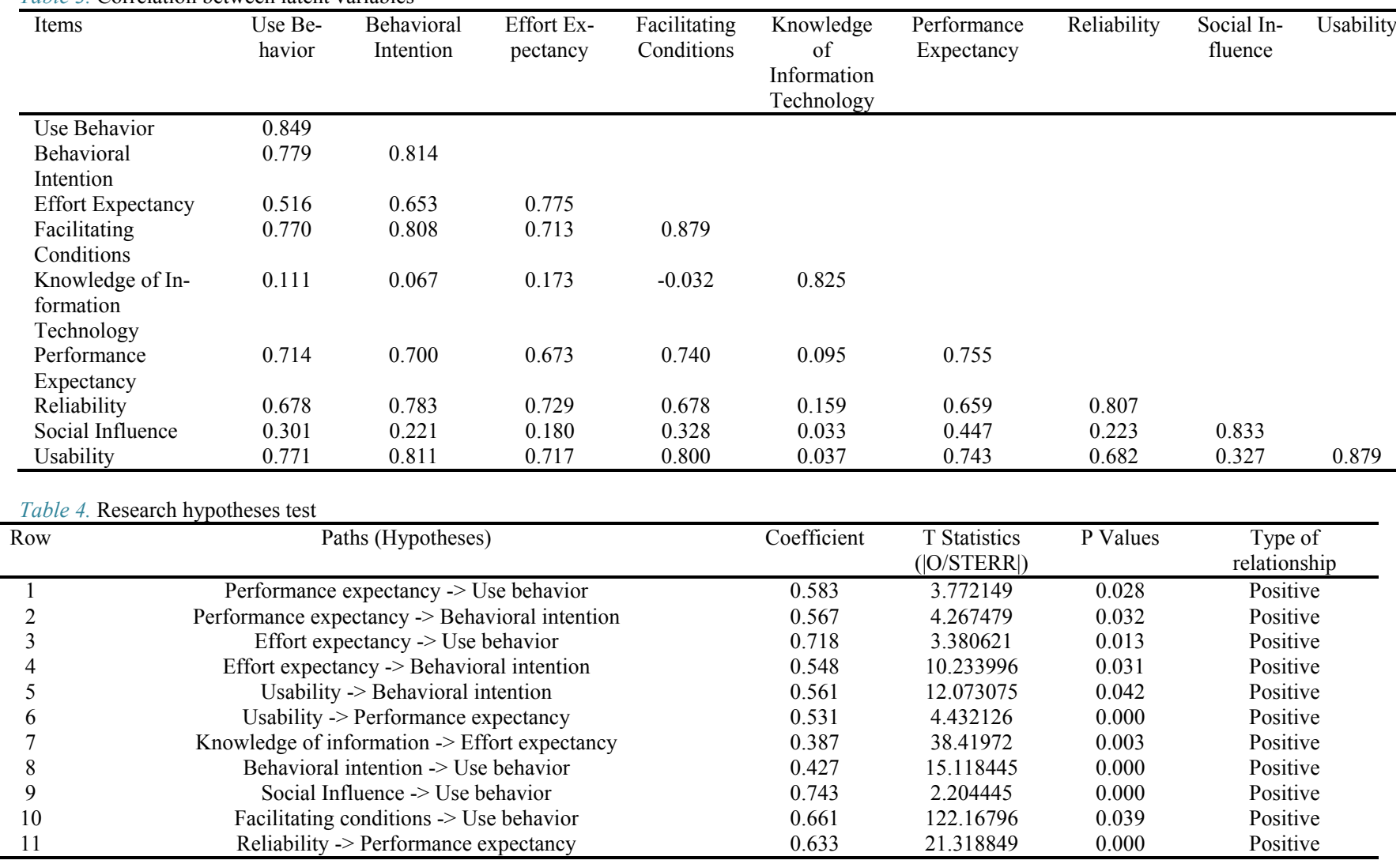




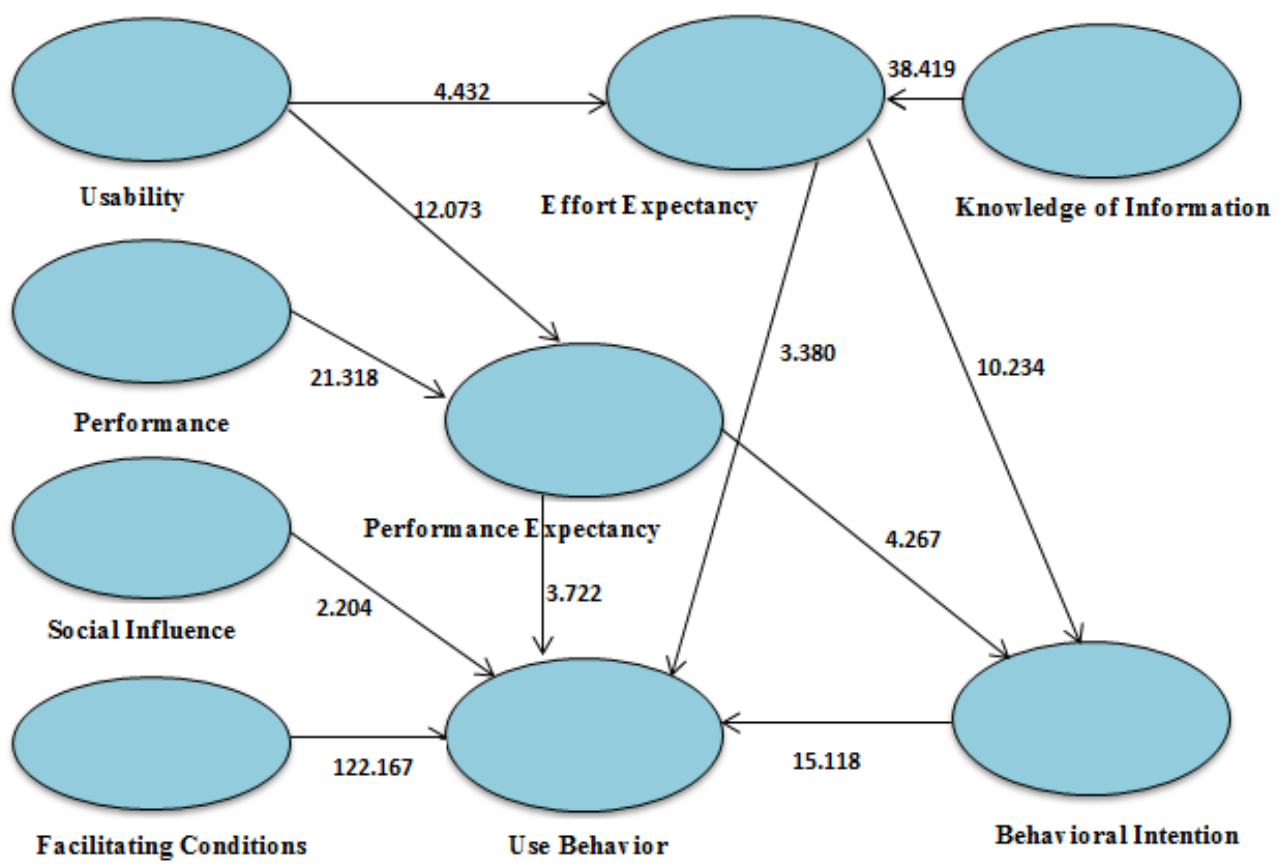

Fig. 3. T-values among variables of the conceptual framework

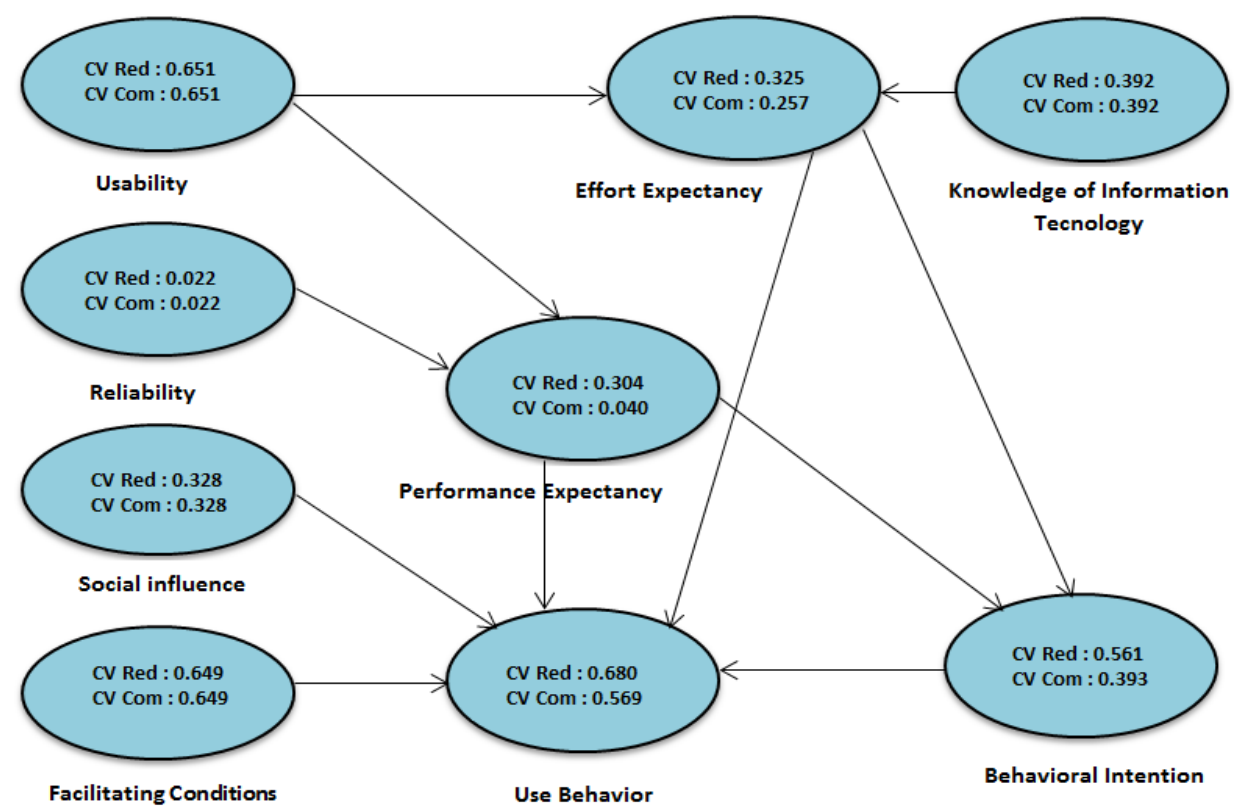

Fig. 4. CV-com index

related to each construct.

Figure 3 and Table 4 demonstrate the value of coefficients between the 2 variables. The variables were extracted from the conceptual framework introduced in the method section (Fig. 1).

Also, because of the positive CV-com index in Figure 4 of the quality model, the measurement quality is appropriate.

\section{Discussion}

In this study we aimed to find effective factors in the acceptance of mobile health technology by hematologists with the help of UTAUT theory. According to the model of the research and theoretical literature using the structural equations modelling based on partial least squares, in the first step the reliability, combinatory validity, external validity, and average variance extracted were examined. In this regard, the obtained results showed that the factor loading of each item on other constructs should be at least 0.1 lower than the factor loading of that item on its construct. This means that factor loading of any item and correlation between latent variables were acceptable, indicating the model possessed appropriate validity. Furthermore, the extracted values variance was greater than 0.5 for each item, 
which is satisfactory. Moreover, the evaluation of the main aim of the research was conducted through the analysis of hypotheses. In this study, the analysis of the hypotheses revealed the variables that were identified in the review of texts as influential variables in the acceptance of mobile health technology were also confirmed in a small phase. Thus, factors and increased reliability and accessibility of this technology in hematologists will lead to a reduction in the side effects of blood transfusions in patients with thalassemia.

This study has investigated more factors compared with previous studies. For example, Venugopal et al (8) examined "expected efforts", "social influence," "behavioral intention," and "facilitating conditions". Another study (13) examined the 3 factors of "perceived ease of use", "perceived usefulness", and "facilitating conditions". "Computer experience" was investigated in one research (17) and "convenience of learning" was examined in another study (18). The studied population also varied in different studies. For example, Bozan et al (14) examined old patients in their study and found older people are not willing to accept technology. In the present study, all factors introduced in the study of Chau and $\mathrm{Hu}$ (21) were examined for technology acceptance, and hematologists were the study population. The results showed that all investigated factors affect the acceptance of technology by hematologists (21).

\section{Conclusion}

Based on the findings of this study, using mobile health technology has not matured yet and many concepts of this technology need more scientific attention, especially in Iran. Moreover, the acceptance of mobile health technology among hematologists and the effective factors in this regard have not been examined prior to this study. According to the results of this study and in order to design applied studies and extract new information in the field of accepting mobile health technology, some of the following suggestions can be mentioned:

1. Investing the acceptance factors of mobile health technology among other medical groups.

2. Evaluating the ability of mobile health technology to ensure the success of the process of medical care.

3. Studying the challenges of using mobile health technology with which people would be faced and the probable solution.

\section{Acknowledgments}

We would like to thank all hematologists, especially those in the Iranian Blood Transfusion Organization that helped us during this research to present a comprehensive study with respect to MHealth technology. The authors also gratefully acknowledge the financial support of Tarbiat Modares University.

\section{Conflict of Interests}

The authors declare that they have no competing interests.

\section{References}

1. Deng Z, Mo X, Liu S. Comparison of the middle-aged and older users' adoption of mobile health services in China. Int $\mathrm{J}$ Med Inform. 2014;83(3):210-24.

2. Park RC, Jung H, Chung K, Yoon K, Applications. Picocell based telemedicine health service for human UX/UI. Multimed Tools Appl. 2015;74(7):2519-34.

3. Mehdipour Y, Khammarnia M, Karimi A, Alipour J, Seyedzaei F, Ebrahimi S. Effective Factors in Acceptance of Mobile Health from Physicians Point of View. J Mod Med Info Sci. 2017;3(1):32-9.

4. Quaosar GAA, Hoque MR, Bao YJT. e-Health. Investigating factors affecting Elderly's intention to use m-health services: An empirical study. Telemed J E Health. 2018;24(4):309-14.

5. Tsai HH, Pong YP, Liang CC, Lin PY, Hsieh C. Teleconsultation by using the mobile camera phone for remote management of the extremity wound: a pilot study. Ann Plast Surg. 2004;53(6):584-7.

6. Terry NP. Mobile health: assessing the barriers. Chest. 2015;147(5):1429-34.

7. Bawack RE, Kala Kamdjoug JR. Adequacy of UTAUT in clinician adoption of health information systems in developing countries: The case of Cameroon. Int J Med Inform. 2018;109:15-22.

8. Venugopal P, Priya SA, Manupati V, Varela M, Machado J, Putnik G, editors. Impact of UTAUT Predictors on the Intention and Usage of Electronic Health Records and Telemedicine from the Perspective of Clinical Staffs. International Conference on Innovation, Engineering and Entrepreneurship; 2018: Springer.

9. Fuad A, Hsu C. UTAUT for HSS: initial framework to study health IT adoption in the developing countries. F1000Res. 2018;7.

10. Shareef MA, Ahmed JU, Kumar V, Kumar U. Effect of mobile phone SMS on m-health: An analysis of consumer perceptions. Handbook of research on cultural and economic impacts of the information society: IGI Global; 2015. p. 284-96.

11. Hsieh HL, Kuo YM, Wang SR, Chuang BK, Tsai CH. A study of personal health record user's behavioral model based on the PMT and UTAUT integrative perspective. Int J Environ Res Public Health. 2016;14(1):8.

12. Dwivedi YK, Shareef MA, Simintiras AC, Lal B, Weerakkody V. A generalised adoption model for services: A cross-country comparison of mobile health (m-health). Gov Inf Q. 2016;33(1):174-87.

13. Garavand A, Samadbeik M, Kafashi M, Abhari S. engineering. Acceptance of Health Information Technologies, Acceptance of Mobile Health: A Review Article. J Biomed Phys Eng. 2017;7(4):403.

14. Bozan K, Davey B, Parker K. Social influence on health IT adoption patterns of the elderly: an institutional theory based use behavior approach. Procedia Comput Sci. 2015;63:517-23.

15. Brown III W, Yen PY, Rojas M, Schnall R. Assessment of the Health IT Usability Evaluation Model (Health-ITUEM) for evaluating mobile health (mHealth) technology. J Biomed Inform. 2013;46(6):1080-7.

16. de Veer AJ, Francke AL. Attitudes of nursing staff towards electronic patient records: a questionnaire survey. Int $J$ Nurs Stud. 2010;47(7):846-54.

17. Zhang N, Guo X, Chen GJTs, technology. IDT-TAM integrated model for IT adoption. Tsinghua Sci Technol. 2008;13(3):306-11.

18. Revere D, Turner AM, Madhavan A, Rambo N, Bugni PF, Kimball $A$, et al. Understanding the information needs of public health practitioners: a literature review to inform design of an interactive digital knowledge management system. J Biomed Inform. 2007;40(4):410-21.

19. Fung EB, Xu Y, Trachtenberg F, Odame I, Kwiatkowski JL, Neufeld $\mathrm{EJ}$, et al. Inadequate dietary intake in patients with thalassemia. J Acad Nutr Diet. 2012;112(7):980-90.

20. Rind DM, Kohane IS, Szolovits P, Safran C, Chueh HC, Barnett GO. Maintaining the confidentiality of medical records shared over the Internet and the World Wide Web. Ann Intern Med. 1997;127(2):13841.

21. Chau PY, Hu PJ. Investigating healthcare professionals' decisions to accept telemedicine technology: an empirical test of competing theories. Inform Manag. 2002;39(4):297-311.

22. Schaper LK, Pervan GP. A model of information and communication technology acceptance and utilisation by occupational therapists. Int $\mathrm{J}$ Med Inform. 2007;130:91-101. 